\title{
Male Breast Cancer: Diagnostic and Prognostic Features in Mali
}

\author{
Iriss A. Darar, Zakari Saye, Bourama Diarra, Madiassa Konaté, Amadou Traoré, Seydou Pamateck, \\ Abdillahi I. Ismail, Arouna Adama Doumbia, Boubacar Karembé, Bakary Tientigui Dembélé, \\ Lassana Kanté, Drissa Traoré, Zimogo Zié Sanogo, Alhassane Traoré, Adégné Togo*
}

Department General Surgery CHU Gabriel Toure, Bamako, Mali

Email: *ap.togo@yahoo.fr

How to cite this paper: Darar, I.A., Saye, Z., Diarra, B., Konaté, M., Traoré, A., Pamateck, S., Ismail, A.I., Doumbia, A.A., Karembé, B., Dembélé, B.T., Kanté, L., Traoré, D., Sanogo, Z.Z., Traoré, A. and Togo, A. (2022) Male Breast Cancer: Diagnostic and Prognostic Features in Mali. Journal of Cancer Therapy, 13, 71-79.

https://doi.org/10.4236/jct.2022.132005

Received: December 13, 2021

Accepted: February 6, 2022

Published: February 9, 2022

Copyright $\odot 2022$ by author(s) and Scientific Research Publishing Inc. This work is licensed under the Creative Commons Attribution International License (CC BY 4.0).

http://creativecommons.org/licenses/by/4.0/

\begin{abstract}
Introduction: Male breast cancer is rare; representing $1 \%$ of breast cancers and less than $1 \%$ of all male neoplasia worldwide. We here analyzed the clinical, histological, therapeutic and prognostic characteristics of male breast cancer in Bamako, Mali. Patients and methods: A retrospective descriptive study was conducted on 14 male patients with breast cancer who visited two university hospitals in Bamako (Hospital Gabriel TOURE and Hospital du Point G) in Mali, from January 2005 to December 2018. Results: Male breast cancer represented $0.63 \%$ of all breast cancers and $0.23 \%$ of all male cancers. The following was observed: the mean age of 53 years (range: 23 - 82); a family history of cancer in 2; breast pain in 9; the average time to consultation of 8 years ( 6 24); gynecomastia found in 1; the tumor palpable in all 14 (size of $5 \mathrm{~cm}$ [3 $10]$ ); ulceration in 5 . The most common histological type was non-specific infiltrating carcinoma with $92.8 \%$. SBR II grade was found in $78.5 \%$ of cases. Of 8 patients with immunohistochemistry, hormone receptor positive was in 13 and Her2 positive was in 5. Metastases were found in 4, 2 pulmonary and 2 hepatic. Treatment: Neoadjuvant chemotherapy in $21.4 \%$; radical surgery in 13 cases; surgery + radiotherapy in 2; surgery + hormonal therapy in 4 . After an average follow-up of 36 months, 1 patient developed a lung metastasis and another patient had a lymph node recurrence. Conclusion: Male breast cancer was detected at relatively later stages. Physicians must be aware of this condition.
\end{abstract}

\section{Keywords}

Breast Cancer, Diagnostic Aspect, Male, Mali, Therapeutic Aspect

\section{Introduction}

Male breast cancer is a rare condition accounting for around $1 \%$ of all breast 
cancers and less than $1 \%$ of all male neoplasms [1]. Its incidence has gradually increased from $0.86 / 100,000$ inhabitants to $1.06 / 100,000$ inhabitants over the past three decades [2] [3]. It is a pathology unknown to the general public, the diagnosis of which is often late making the prognosis more reserved [2] [4]. There are well-codified guidelines for therapeutic management in women, which is not the case in men given the small number of prospective randomized studies on this type of disease. Conservative surgical treatment rarely finds its place in the treatment of breast cancer in men, on the one hand, due to the small breast volume and, on the other hand, the easy acceptance of mastectomy. On the other hand, all the other treatments, surgical (axillary dissection or sentinel lymph node), radiotherapy, chemotherapy, hormone therapy (tamoxifen or antiaromatases) and biotherapy (trastuzumab) can be part of the therapeutic arsenal at our disposal to fight this rare form of cancer [5].

In Mali, there are no data describing the clinical characteristics as well as the treatments of men with breast cancer. This is why we undertook this multicenter study in order to describe the clinical, diagnostic, therapeutic and prognostic characteristics of breast cancer in humans in the general surgery departments of CHU Gabriel Touré, of Surgery B and of surgery A of CHU, from Point G in Bamako.

\section{Methods and Patients}

This is a descriptive retrospective multicenter study from January 2005 to December 2018, i.e. 14 years, bringing together the general surgery departments of CHU Gabriel Touré, Surgery B and Surgery A of CHU du Point G.

The inclusion criteria were male patients of all ages, presenting primary unilateral, bilateral, localized, locally advanced or metastatic breast cancer confirmed histologically and having benefited from treatment in the University hospitals of Point $G$ and Gabriel Touré. The exclusion criteria were female sex, male patients with another breast lesion, inoperative medical files. Thus, we retained 14 files in total. The files were analyzed according to a pre-established operating sheet including clinical, paraclinical, therapeutic and evolutionary characteristics. The diagnosis of breast cancer was made by biopsy of the tumor, staging was established according to the new TNM classification.

The histopronostic grade was established according to the SBR-EE histological system (Scarf Bloom and Richardson), the immunohistochemical study to determine the status of hormone receptors, and the hercept test. Overall and specific survival was analyzed according to the Kaplan-Meier method. The statistical analysis of the data was carried out by the software Epi info 6 .

\section{Results}

During the study period, we collected 14 cases of male breast cancer, representing $0.63 \%$ of breast cancers and $0.23 \%$ of cancers in men. The clinical, histological and therapeutic characteristics of the patients are summarized in Tables 1-3. 
Table 1. Clinical, histological and therapeutic characteristics of patients.

\begin{tabular}{|c|c|}
\hline Characteristics & $\mathrm{N}=14$ \\
\hline Average age (years) & $53(23-82)$ \\
\hline \multicolumn{2}{|l|}{ Background: } \\
\hline Family & $2(14.3 \%)$ \\
\hline gynecomastia & $1(7.1 \%)$ \\
\hline \multicolumn{2}{|l|}{ BMI: } \\
\hline$<25$ & $7(50 \%)$ \\
\hline $25-30$ & $4(28.6 \%)$ \\
\hline$>30$ & $3(21.4 \%)$ \\
\hline \multicolumn{2}{|l|}{ Mode of discovery: } \\
\hline Nodule & $14(100 \%)$ \\
\hline Ulceration & $5(35.7 \%)$ \\
\hline Retraction & $4(28.6 \%)$ \\
\hline Flow & $5(35.7 \%)$ \\
\hline \multicolumn{2}{|l|}{ cTNM: } \\
\hline T0 & 0 \\
\hline $\mathrm{T} 1$ & 0 \\
\hline $\mathrm{T} 2$ & $2(14.3 \%)$ \\
\hline T3 & $3(21.4 \%)$ \\
\hline $\mathrm{T} 4$ & $9(64.3 \%)$ \\
\hline No & $8(57.1 \%)$ \\
\hline N1 & $4(28.6 \%)$ \\
\hline $\mathrm{N} 2$ & $2(14.3 \%)$ \\
\hline MO & $11(78.6 \%)$ \\
\hline M1 & $3(21.4 \%)$ \\
\hline
\end{tabular}

Table 2. Histological characteristics of patients.

\begin{tabular}{cc}
\hline Characteristics & $\mathrm{N}=14$ \\
\hline Grade SBR: & 0 \\
SBR I & $11(78.5 \%)$ \\
SBR II & $3(21.5 \%)$ \\
SBR III & \\
Receptors. & $7 / 8(87.5 \%)$ \\
RE+ & $6 / 8(75 \%)$ \\
RP+ & $5 / 8(62.5 \%)$ \\
HER2+ & \\
\hline Histological type: & $13(92.8 \%)$ \\
CINS & $1(7.2 \%)$ \\
CLI & \\
\hline
\end{tabular}


Table 3. Therapeutic characteristics of patients.

\begin{tabular}{cc}
\hline Characteristics & $\mathbf{N}=\mathbf{1 4}$ \\
\hline Treatment. & \\
Mastectomy & $13(92.8 \%)$ \\
No surgery & $1(7.2 \%)$ \\
Radiotherapy & $2(14.3 \%)$ \\
Chemotherapy & $12(85.7 \%)$ \\
Hormonotherapy & $4(35.2 \%)$ \\
\hline
\end{tabular}

The average age of the patients was 53 years with extremes of 23 and 82 years. Alcoholism and smoking were found in 08 patients, i.e. $57.1 \%$ of cases. A family history of breast cancer was found in 2 patients (14.3\%). Gynecomastia was found in one patient (7.1\%).

The BMI was calculated in all of our patients, $25 \%$ of them were overweight and $25 \%$ were obese. The majority of patients (9/14) presented with breast pain. The average consultation time was 08 years (range: 6 - 24). The left breast was the most affected with $64 \%$ of cases. Ulceration was noted in 5 cases, i.e. $35.7 \%$ of cases (Figure 1). It was a palpable tumor in all patients with an average size of $5 \mathrm{~cm}$ with extremes of $3 \mathrm{~cm}$ and $10 \mathrm{~cm}$ (Figure 2) and retroareolar localization in $68 \%$ of cases. Breast discharge was present in $35.7 \%$ of patients, and hematic in $60 \%$ of cases. The most represented histological type was infiltrating carcinoma of the nonspecific type with $92.8 \%$. Lobular carcinoma was found in 1 patient $(7.2 \%)$.

SBR II grade was found in $78.5 \%$ of cases and grade III in 3 cases $(21.5 \%)$. Immunohistochemistry was performed in $8 / 14$ patients $(57.2 \%)$. The estrogen receptors were positive in 7 patients $(87.5 \%)$. Progesterone receptors were positive in 6 patients (75\%) and HER2 overexpression was found in 5 patients (62.5\%). Lymph node involvement was described in 6 cases (42.8\%). Four patients were metastatic, 2 of which were pulmonary and 2 were hepatic. UICC stage III was the most common, accounting for $50 \%$ of cases. Thirteen patients $(92.8 \%)$ underwent radical surgery (a Madden mastectomy). This mastectomy was associated with axillary dissection in $84.6 \%$ of cases. The postoperative course was complicated by infection of the lining in one patient and two cases of lymphedema.

Chemotherapy was performed in 12 patients, 4 as a neoadjuvant and 8 as an adjuvant. Hormone therapy was successful in 4 patients, or $35.2 \%$ of cases. Only 2 patients (14.3\%) received postoperative radiotherapy.

The median follow-up of the patients in our study was 36 months with extremes of 6 to 60 months. Of all the patients, $11(78.6 \%)$ are considered to be in complete remission. A case of lymph node recurrence was detected in our series 2 years after surgical treatment. One patient developed lung metastasis 3 years after surgical treatment. Overall survival was $78.6 \%$ after 12 months, $69.2 \%$ after 


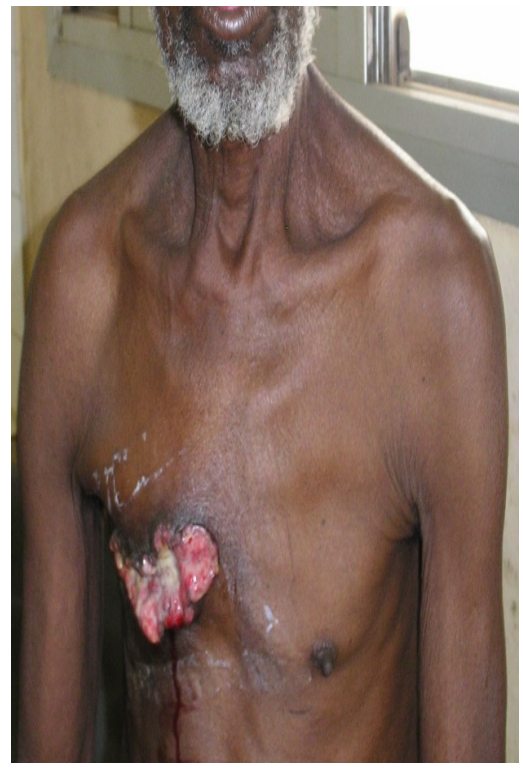

Figure 1. Tumour of the right breast.

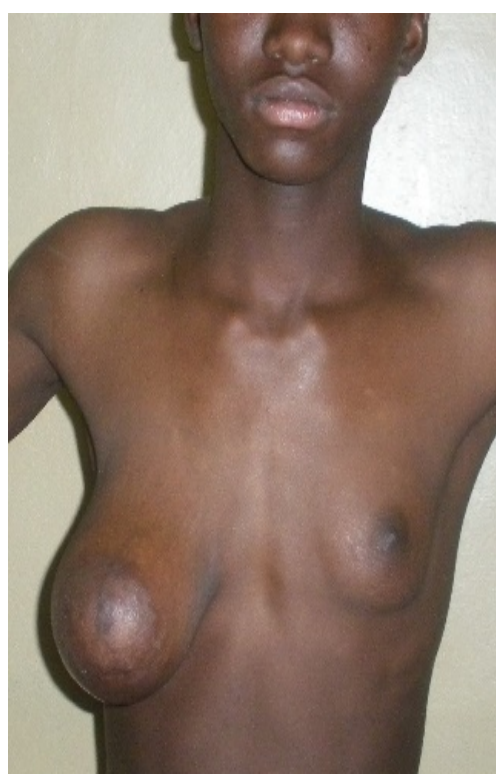

Figure 2. Large right breast tumour and left gynaecomastia.

24 months (including 2 patients lost to follow-up) and $42.9 \%$ after 60 months with $3(21.4 \%)$ deaths and 5 lost of seen. We assessed survival as a function of stage and as a function of SBR histopronostic grade. The 5-year stage survival was $100 \%$ for stages I, $60 \%$ for stages II, $18 \%$ for stages III and $10 \%$ for stages IV. That according to SBR histopronostic grade was $45 \%$ for grades II and $20 \%$ for grades III.

\section{Discussion}

The frequency of breast cancer in men compared to all cancers in the male population is estimated to be between $0.2 \%$ and $1.5 \%$ [6]. Its frequency rate relative 
to that of women is of the order of $1 \%$ with extremes ranging from $0.6 \%$ to $1.6 \%$ [6] [7]. The highest rates are found in some African countries [6]. In our study, it represents $0.23 \%$ of cancers in men and $0.63 \%$ of breast cancers of all sexes.

The average age of breast cancer onset in men is around 60, ten years later than in women [8]. Indeed, its incidence increases with age [7]. In our series, the average age is 53 years $(23-82)$.

The etiopathogenesis of breast cancer in men is still unknown [8] [9]. Certain predisposing factors have been identified. These are mainly pathological situations with a common factor represented by an abnormality of hormonal metabolism related to relative hyperestrogenia or hyperprolactinemia [8]. The notion of family and genetic history is found in $5 \%$ to $10 \%$ of cases [3] [5]. This notion of "breast cancer families" is related to the existence of genetic mutations involving many genes, the most common of which are: BRCA1, BRCA2, p53 and c-erbB-2 [8] [9].

The contributing factors statistically confirmed by several studies are:

- A family history of breast cancer and especially breast cancer among the first degree collaterals [5];

- The existence of a mutation for the BRCA2 gene [9];

- Male infertility: it seems to increase the risk of breast carcinoma in men [10];

- Obesity, which is thought to be responsible for an increased conversion of androgens to estrogens by peripheral aromatization in adipose tissue [11].

Invasive ductal carcinoma is the most common histological type (70\% - 95\%)

[5] [6] [7] [8] [9]. In our series, invasive ductal carcinoma was the predominant histological type with $92.8 \%$ of cases. Intracanal carcinoma is the second largest. Lobular carcinoma is virtually non-existent in men because lobules do not develop normally in the male breast. Lymph node invasion is found in $40 \%$ to $75 \%$ of cases [8] (42.8\% in our series). This high rate is explained by the central topography of the cancer and the small size of the male mammary gland. Axillary invasion is correlated with tumor size and histological type.

The hormone receptors for progesterone (RP) and estrogen (ER) are more frequently positive than in women with often very high levels $65 \%$ to $90 \%$ of cases depending on the series [7] [8] [9] [12] [13], those with estrogen in 65\% to $86 \%$ and those with progesterone in $67 \%$ to $80 \%$. In our series, in the 8 patients where they were sought, the rates were $87.5 \%$ for RE and $75 \%$ for RP.

The most frequent clinical presentation is a hard, retroareolar, painless swelling in $68 \%$ to $85 \%$ in the literature [14] [15] and it is represented in $68 \%$ of our patients. Breast cancer in men seems to have a worse prognosis than in women [13], but this is due to a later discovery and therefore at a more advanced stage in men. The mean consultation time reported by studies conducted by Tounon de Lara [14] and Mohammed [16] are 22.5 months and 24 months respectively. On the other hand, in our series, this period was 192 months with the extremes of 2 and 24 years. This could be explained by the lack of awareness of this disease which leads to delayed diagnosis in man. 
The therapeutic indications depend on the histological type of the tumor, the lymph node involvement, the clinical stage of the affection and the general condition of the patient: curative treatment is used for localized tumors, however, in the forms invasive with metastatic spread, the treatment is palliative aimed at a better quality of life [17].

Surgery is the first-line treatment, it is based on a modified radical mastectomy with axillary lymph node dissection according to Patey [17]. Due to the small size of the mammary gland in men and the rapidity of tumor extension, conservative surgery is rarely indicated [7].

To our knowledge, no prospective trials have been performed in humans with adjuvant therapy [18].

However, given the average age of the patients, the many diseases often associated, the frequent and elevated positivity of hormone receptors, hormone therapy is offered as a first-line treatment [7] [8] [9] [12] [13]. The reference molecule is tamoxifen, used as an adjuvant treatment [18]. But in our study hormone therapy was performed in $35.2 \%$ of cases. No patient received targeted therapy (trastuzumab) although HER2 overexpression was found to be present in 5 patients. This would explain by the high cost and the inaccessibility of the treatment.

Given the frequent involvement of the skin and/or the nipple, as well as the frequency of axillary lymph node involvement, locoregional radiotherapy is very often indicated at the level of the wall and the scar [19]. Chemotherapy is considered part of both curative and palliative treatment. The protocols used are comparable to those adopted for cancer in women. It is most often a combination chemotherapy [8].

The prognosis depends on several clinical, histological and biological parameters [8]: International Union against Cancer (UICC) clinical stage, histological type, lymph node involvement, SBR grade, vascular emboli and hormone receptor expression.

The prognosis depends on several clinical, histological and biological parameters [8]: the clinical stage of the International Union against Cancer (UICC), the histological type, lymph node involvement, the SBR grade, vascular emboli and expression hormone receptors. Breast cancer in men is said to have a worse prognosis than that in women [13]. However, survival is similar to that of female breast cancer when comparing survival rates corrected for excluding deaths from intercurrent disease or second cancer. In our series, we assessed survival as a function of stage and as a function of histopronostic grade SBR. The stage of progression is an important factor in survival in breast cancer in men, it decreases with increasing stage. We noted a decrease in survival time as a function of the histopronostic grade of SBR.

\section{Conclusion}

Breast cancer in men is a rare and serious entity, the incidence of which is said to 
be sharply increasing in people over the age of fifty. In sub-Saharan Africa, this rarity coupled with ignorance and recourse to traditional medicine that the diagnosis is made late, doctors must be aware of this condition.

\section{Conflicts of Interest}

The authors declare no conflicts of interest regarding the publication of this paper.

\section{References}

[1] Arnauld, N., Pouget, O., Gharbi, M. and Berttes, J.P. (2006) Cancer du sein chez l'homme: Existe-t-il une similitude avec le cancer du sein chez la femme? Gynécologie Obstétrique \& Fertilité, 34, 413-419. https://doi.org/10.1016/j.gyobfe.2006.03.014

[2] Weiss, J.R., Moysich, K.B. and Swede, H. (2005) Epidemiology of Male Breast Cancer. Cancer Epidemiology, Biomarkers \& Prevention, 14, 20-26.

[3] Giordano, S.H., Cohen, D.S. and Buzdar, A.U. (2004) Breast Carcinoma in Men: A Population Based Study. Cancer, 101, 51-57. https://doi.org/10.1002/cncr.20312

[4] Donegan, W.L., Redlich, P.N., Lang, P.J. and Gall, M.T. (1998) Carcinoma of the Breast in Males. A Multi Institutional Surgery. Cancer, 83, 498-509. https://doi.org/10.1002/(SICI)1097-0142(19980801)83:3\%3C498::AID-CNCR19\%3E 3.0.CO;2-R

[5] Comet, B., Cutuli, B., Penault-Llorca, F., Bonneterre, J. and Belkacémi, Y. (2009) Cancer du sein chez l'homme: Revue de la littérature. Bulletin du Cancer, 96, 181-189. https://doi.org/10.1684/bdc.2008.0813

[6] Oger, A.-S., Boukerrou, M., Cutuli, B., Campion, L., Rousseau, E., Bussières, E., et al. (2015) Le cancer du sein chez l'homme: Approche épidémiologique, diagnostique, et thérapeutique: Étude multicentrique rétrospective à propos de 95 cas. Gynécologie Obstétrique \& Fertilité, 43, 290-296. https://doi.org/10.1016/j.gyobfe.2015.02.010

[7] Benchellal, Z., Wagner, A., Harchaoui, Y., Huten, N. and Body, G. (2002) Cancer du sein chez l'homme: À propos de 19 cas. Annales de Chirurgie, 127, 619-623. https://doi.org/10.1016/S0003-3944(02)00816-7

[8] Alaoui Slimani, K., Debbagh, A., Sbitti, Y., Errihani, H. and Ichou, M. (2016) Cancer du sein chez l'homme au Maroc: Épidémiologie et facteurs pronostiques. A propos de 140 cas. Gynécologie Obstétrique \& Fertilité, 44, 636-640. https://doi.org/10.1016/j.gyobfe.2016.08.009

[9] Cutuli, B.F., Velten, M. and Forentz, P. (1993) Cancer du sein chez l'homme: 126 observations. La Presse Médicale, 22, Article No. 463.

[10] Gordon, D.J., Chin, K.H., Budny, P.G. and Taylor, A.R. (2003) Male Breast Cancer in World War II Aviation: A Case Report and Review. Breast, 12, 156-157. https://doi.org/10.1016/S0960-9776(02)00282-5

[11] Giordano, S.H. and Hortobagyi, G.N. (2006) Leuprolide Acetate plus Aromatase Inhibition for Male Breast Cancer. Journal of Clinical Oncology, 24, 42-43. https://doi.org/10.1200/JCO.2006.07.2397

[12] Elbachiri, M., Fatima, S., Bouchbika, Z., Benchekroun, N., Jouhadi, H., Tawfiq, N., et al. (2017) Cancer du sein chez l'homme: À propos de 40 cas et revue de la littérature. Pan African Medical Journal, 28, Article No. 287. https://doi.org/10.11604/pamj.2017.28.287.13527

[13] El Mhabrech, H., Neji, H., Stita, W., Mallat, N., Aissa, A., Chabchoub, I., et al. 
(2014) Le cancer du sein chez l'homme: Similaire ou différent à celui de la femme. Feuillets de radiologie, 54, 264. https://doi.org/10.1016/j.frad.2014.01.005

[14] Tunon de Lara, C., Goudy, G., MacGrogan, G., Durand, M., Dilhuydy, J.-M., Avril, A., Stoeckle, E., et al. (2008) Cancers du sein chez l'homme: À propos de 52 cas pris en charge à l'institut Bergonié de Bordeaux entre 1980 et 2004. Gynécologie Obstétrique \& Fertilité, 36, 386-394. https://doi.org/10.1016/j.gyobfe.2008.02.020

[15] Zineb, H. (2016) Cancer du sein chez l'homme à propos de 16 cas, Thèse Med, Université Sidi Mohamed Ben Abdallah Maroc, Fes, 161 p.

[16] Lamghari, M. (2017) Cancer du sein chez l'homme: À propos de 13 cas. Thèse Méd, Université Mohamed V, Rabat, 105 p.

[17] Gennari, R., Curigliano, G., Jereczek-Fossa, B.A., Zurrida, S., Renne, G., Intra, M., et al. (2004) Male Breast Cancer: A Special Therapeutic Problem. Anything New? International Journal of Oncology, 24, 663-670. https://doi.org/10.3892/ijo.24.3.663

[18] Fogh, S., Hirsch, A.E., Langmead, J.P., Goldberg, S.I., Rosenberg, C.L., Taghian, A.G., et al. (2011) Use of Tamoxifen with Postsurgical Irradiation May Improve Survival in Estrogen and Progesterone Receptor-Positive Male Breast Cancer. Clinical Breast Cancer, 11, 39-45. https://doi.org/10.3816/CBC.2011.n.007

[19] Yoney, A., Kucuk, A. and Unsal, M. (2009) Male Breast Cancer: A Retrospective Analysis. Cancer/ Radiotherapeutic, 13, 103-107.

https://doi.org/10.1016/j.canrad.2008.11.011 